\title{
Learning Communities for First-Year Faculty: Transition, Acculturation, and Transformation
}

\author{
Harriet Fayne, Leslie Ortquist-Ahrens \\ Otterbein College
}

To enhance new faculty members' chances for teaching and career success, Otterbein College piloted a yearlong learning community program and encouraged first-year faculty to participate. Four new faculty members took part in opportunities designed to enhance their teaching, to orient them more fully to a new institution and student body, to foster collegial community, to encourage reflective practice, and to introduce them to the scholarship of teaching and learning. This qualitative case study tracks their developmental trajectory, which led them from an initial concern with self and survival to an eventual focus on student learning.

\section{Introduction}

There is consensus among higher education professional development scholars that academic careers, while viewed as idyllic from outside of the academy, pose significant challenges, particularly to newcomers. A recent largescale study (Rice, Sorcinelli, \& Austin, 2000) reinforced themes identified in case studies conducted at one or more higher education institutions (Boice, 1991; Menges, 1996; Sorcinelli, 1988). While new faculty members tend to be highly committed and enthusiastic about their choice of career, they often experience negative emotions and obstacles early on that can temper their idealism and reduce their effectiveness. For many, the entry period (lasting from one term to several years) is marked by anxiety, pressure, and stress stemming from ambiguous expectations, a sense of isolation, and a lack of balance between personal and professional life. 
Career entry involves learning the explicit and implicit norms, beliefs, and values of three separate cultures: the academy, the discipline, and the particular institution (Lucas \& Murry, 2002). Graduate schools socialize their students for the first two years using an apprenticeship model. As research and teaching assistants, future faculty are acculturated into the world of the research university. However, these same well-trained and knowledgeable graduate students become novices in institutions that are likely to be very different from their research universities. Furthermore, preparedness for the classroom varies widely. Despite the increasing availability of TA training and Preparing Future Faculty programs, many new faculty still arrive with limited teaching experience and little or no formal training. The dissonance between the images of the professoriate acquired during the long years of training and the realities of life in comprehensive universities, liberal arts colleges, and community colleges, where one's teaching is often more central than one's research, can be a major source of stress.

Baldwin (1990) outlines several key tasks of the career entry stage. New faculty usually have to design several courses in a limited period of time, some or all of which may be outside of their areas of expertise; they must fine-tune their teaching skills; they must figure out how to continue to stay involved in scholarly pursuits in face of heavy teaching demands; and they must figure out what the institution requires of them in terms of service to the department, college/university, and community.

According to Rosch and Reich (1996), the acculturation process takes place in four sub-stages: pre-arrival (during graduate school), encounter (recruitment and orientation), adaptation (initial period of reconciling expectations and reality), and commitment (settling into routines and finding a niche). It is during the adaptation sub-stage that locally created induction programs can have their greatest impact. Ideally, these programs should help novices acquire new skills, develop an appreciation for the visible and invisible dimensions of institutional culture (Lucas \& Murry, 2002) and increase participants' self-knowledge about their place within that culture.

Induction programs to help new faculty adapt come in many different forms (Cox, 1995). Orientation sessions for new faculty have the longest history; they range from one-day meetings to a series of social and educational activities across the first year. Lucas and Murry (2002) report that mentoring programs, a workplace learning model that involves the assignment of a more experienced peer to a beginner, are increasing in popularity.

However, the literature on mentoring practices at the pre-collegiate level offers some cautionary tales to higher education professional developers. Meyer (2000) argues that mentor-mentee relationships tend to be 
instrumental; pairs focus on the immediate and the particular, often missing opportunities for deeper exploration of the why/why not questions. What's more, inherent in some mentoring programs is a conservative bias. Rather than encouraging new teachers to find their own professional identity or to participate in new initiatives important to the institution, such programs may unintentionally or intentionally indoctrinate rather than acculturate (New South Wales, Department of Education and Training, 2002). In his study of mentoring pairs in higher education, Boice (1992), too, suggests that while highly structured pairings can help newcomers become acculturated more quickly, there can be a "dark side" to mentoring relationships as they are usually practiced. Without external structuring and guidance, the relationship often founders. Even when it doesn't, pairs can get mired in narrow preoccupations related to pragmatic immediacies. Mentors generally hesitate to intervene in truly significant and formative ways unless they, too, are mentored and coached.

\section{Learning Communities: An Option for New Faculty}

How then to develop effective programming that will help new faculty adapt to the specifics of their new positions and new institutions, taking advantage of their plasticity during the third sub-stage of the acculturation process? Junior faculty learning communities provide an alternative model that adds a new dimension to mentorship programs. The Teaching Scholars Program at Miami University Ohio, which began in 1978, has served as a model for other institutions. Miami's program invites faculty in years two through five at the institution to participate. Nine to thirteen participants are selected; activities span across two semesters and include seminars, retreats, attendance at national conferences, work with at least one self-selected mentor, and the completion of a teaching project, usually a course mini-portfolio or an action research project (Cox, 1995). While the program does include individual mentoring relationships, one unique aspect is its emphasis on the cohort group. Program evaluations reveal that the strongest program impact is "colleagueship" and the strongest outcome is "participants' interest in the teaching process" (Cox, 1995, p. 291). Across the two semesters, new faculty move from "discussions of 'how to' topics led by experts to more controversial or philosophical topics, such as ethical dilemmas in teaching, often led by a member of the group" (p. 294).

If a junior faculty learning community has such a profound impact on participants, why not include first-year faculty in the mix? Cox (1997) advises 
against this: "First year faculty are not eligible for the Teaching Scholars Program because the Program's designers believed that a professor's initial year is necessarily focused on adjusting to and getting comfortable with the department" (p. 259).

In preparing to introduce the learning community model at Otterbein College, the director of the Center for Teaching and Learning decided, based on institutional context and needs, to break the mold and not only invite but strongly encourage first-year faculty to participate. While Cox's choice at Miami involved conceiving of the department as the first and primary context for induction-a choice which may make sense at a research-oriented institution with large departments-this model seemed less satisfactory for helping new faculty adapt quickly to the culture of a small comprehensive college with a strong regional character, a multitude of first-generation students, and a strong liberal arts tradition-all of which is likely to be new to many incoming colleagues.

Furthermore, the decision to include first-year faculty rested on concerns about classroom incivilities that may plague and derail them and about the lasting patterns of success and failure established for many in the first year. Boice (2000) points out that it is during that first year when faculty are most likely to experience classroom incivilities that "make or break us as teachers" (p. 81). He lists the following as examples of student incivilities that many new faculty find themselves poorly prepared to deal with: cutting class, arriving late, cheating, distracting the instructor or classmates, refusing to participate, and coming to class unprepared. A learning community provides a forum to discuss these incivilities and to learn how to address them promptly. Facilitators and other early career faculty, particularly "quick starters" who have no trouble establishing rapport with their students and have relaxed, effective teaching styles (Boice, 1991), could be helpful in identifying ways to address or prevent them. If department chairs or senior department colleagues are acting as mentors, new professors may be less likely to disclose frustrations and failures, as these colleagues will eventually evaluate their work.

Equally significant, although not as immediate as classroom management issues, was the need to provide opportunities for new faculty to reflect upon beliefs, assumptions, and actions with the intent of encouraging more self-awareness. Robertson (1999), in his developmental model of college teaching, posited that faculty in their early years at an institution are likely to be egocentric, teacher-centered, and content-driven. Without a safe place to analyze "teaching failures" (p. 278), they may not move beyond "egocentrism" to learner-centeredness and finally to an understanding of the "intersubjective dynamics among learners and teachers" (p. 282). Key readings and 
conversations would pair with reflections on classroom experience to help shift new faculty members from an intense concern with self and survival to a focus on teaching strategies and fostering student learning. Self-evaluation skills that would be critical for long-term success (McMillin \& Berberet, 2002) could be developed and encouraged. The mutuality and trust established in learning communities might encourage conversation and risk-taking (Harper, 1996) and allow for "reflection-in-action" (Schön, 1987).

The decision to open the pilot junior faculty learning community to new hires was likely to impact both process and product, and it remained to be seen whether first-year faculty would benefit from such an induction experience. We thus designed a qualitative case study to address the following questions about the value and effectiveness of the learning community as an induction experience and in terms of its ability to encourage development as reflective practitioners:

- Was the New Faculty Professional Learning Community (PLC) able to induct its members into the larger campus community by providing a vehicle for acculturation, skill acquisition, and reflection?

- Did the group's conversation begin with a survival focus, move to a task orientation, and culminate in discussions about impact as would be predicted by career development theory?

- Did individual teaching projects demonstrate "reflection-in-action"?

\section{Context}

Otterbein College is a private, co-educational comprehensive college located in a suburb of Columbus, Ohio. While the vast majority of the student body of approximately 3,000 comes from the surrounding part of the state, in 2003-2004, students were drawn from 28 states and 24 foreign countries; 2,096 of those enrolled were full-time undergraduate students; 578 were parttime students; and 358 were graduate students enrolled in master's programs in business, education, and nursing. Approximately $35 \%$ of freshmen are first-generation students (a figure that has remained relatively constant over the past several decades), and $90 \%$ receive some sort of financial aid.

In May 2003, the Center for Teaching and Learning received a grant from the McGregor Fund to support seven PLCs over a three-year period. One track annually is open to a cohort of five to eight junior faculty members who are in their first three years at Otterbein, and incoming faculty members are especially encouraged to participate. This sustained development 
opportunity is designed to reach significantly beyond the new faculty orientation and mentoring programs that have already been in place at Otterbein for a number of years.

\section{Participants}

While five individuals applied and were selected for participation, only four could truly be called new or junior faculty. One participant, a student affairs administrator, had been with the college for fifteen years but was embarking on a new journey by agreeing to teach a section of freshman English. Though she was an "apprentice" teacher, she knew the local culture well and had a firm grounding in student development theories. She was thus able to serve as a translator of campus culture, acting as a de facto co-facilitator for the group with the CTL director, who facilitated this learning community.

The four new faculty members came together from different disciplinesart history, communication, English, and mathematics, representing four of the five academic divisions at the college-and brought a wide range of preparation and prior teaching experiences to the table. One newcomer had had only limited experience and essentially no formal training in pedagogy. The other participants had had more preparation and experience, ranging from teaching assistant training during graduate school to faculty development opportunities while serving as visiting professors elsewhere. One participant was a graduate of a teacher education program before returning to graduate school to pursue her Ph.D.; another had participated in a Preparing Future Faculty program as part of her graduate experience. Two of the newcomers had some prior experience teaching at Otterbein: one had taught a summer course, and the second had completed her first year on a tenure-track line.

\section{Life Cycle of the New Faculty Learning Community}

\section{Fall Term: Survival}

From the outset, the group developed and progressed collaboratively and democratically, choosing target readings, activities, projects, and conference attendance by consensus. Responsibility for developing questions and leading discussion at meetings rotated among members as did hosting of the meetings in participants' homes. The decision to meet in a home selting helped to distinguish learning community sessions from formal meetings or seminars held on campus. It also provided a context that allowed participants to get to know one another as people, not just as colleagues. 
As focus texts for the year, the members selected Brookfield's (1995) Becoming a Critically Reflective Teacher (1995) and Bransford, Brown, and Cocking's (2000) How People Learn: Brain, Mind, Experience, and School. In addition, they read a range of articles contributed by members of the group as these became relevant, and they consulted two reference texts for assessment and teaching ideas: Angelo and Cross's (1993) Classroom Assessment Techniques: A Handbook for College Teachers and Davis's (1993) Tools for Teaching. The group spent approximately half of each meeting discussing the texts. Readings on active learning strategies by Nelson (1997), Frederick (1989), and Angelo (1993) proved to be very useful, as did one by Lewis (1994) about soliciting ongoing student feedback. Less well received, particularly early on in the life of the community, were more theoretical selections.

Group members quickly learned to value the sense of connection and belonging they felt in the learning community. While not initially part of the proposed structure for the group, participants in the learning community found it extremely important to dedicate half of each meeting to a sharing of teaching highs and lows from the past two weeks. Doing so helped these newcomers to the institution (or to teaching) work through the adjustment to a new culture, a new student body, and new expectations-in a safe and supportive context. At the same time, gradual self-disclosures and risk-taking in sharing failures and challenges as well as successes built a strong foundation of trust. It was particularly helpful for them to experience support and collegiality with others in the same phase of adjustment and with colleagues from outside of their department contexts.

All four new faculty members found the students in their classrooms at Otterbein significantly different from previous students they had taught during their graduate programs. During fall quarter, new faculty brought stories to the group that often involved classroom incivilitics or other perplexing situations. Serving as a cultural tour guide, the student affairs administrator, with years of experience at the institution, provided feedback as to whether the behaviors described were typical or atypical at Otterbein. In turn, participants and the facilitator provided instructional ideas, relevant readings, and moral support. Conversations also included discussions of department cultures and experiences serving on college committees; participants considered how to navigate the politics of the institution. Collegial and mutually supportive relationships began to emerge as the learning community members checked in with one another regularly and followed one another's progress in addressing old problems, meeting new challenges, and experiencing new successes. Frequently, this informal time of catching up and exchanging experiences was interwoven with thoughtful observations gleaned from the day's scholarly readings. 
A key shared experience for the members of this community involved attendance at the Lilly Conference on College Teaching in Oxford, Ohio. Rather than use learning community stipends of $\$ 250$ for the academic year to support their individual teaching projects, the participants unanimously decided to attend the conference together in November. This experience proved pivotal, first, because it gave members a good opportunity to get to know one another better, and second, because the presentations on college teaching and student learning were of high quality. It was the first time any of the participants had attended a conference devoted solely to college-level pedagogy. One participant reflected on several sessions where, as she put it, "the light came on" and there were "moments that encouraged a more mindful pedagogical stance. I was grateful for the opportunity to attend the conference. Holistically, it was a register of the kind of research, professional development, and teaching the learning community can nurture."

\section{Winter Term: Getting Down to Business}

Trying to understand first-generation college students was a major focus of discussion during the winter term. Otterbein considers itself a college of opportunity, attracting sizable numbers of traditional and adult students who have limited exposure to the culture of the academy. Learning community members discussed the impact of background on classroom behavior and disconnects between their expectations of typical college students and realities encountered in their classes. By midyear, group members realized that their assumptions had been based in large measure on their own student identities, which were quite different than their students'. One perplexed participant, whose wry, ironic humor was at odds with her students', posted the following on the PLC discussion board: "I sometimes think that I seem way too strange to these students."

As group members became more comfortable with one another (and more exhausted), the tone of the meetings shifted, taking on a marked note of frustration and a relatively exclusive focus on student behavior and challenges posed by students: How can we get our jobs done when we have troublesome students who challenge our right to assign analysis papers, refuse to participate in group activities, and write scathing criticisms on course evaluations? Are we required to modify assignments for adult students? Why aren't majors willing to accept challenges in their field of study? Why do my students overreact when they have trouble with directions? How do I get students to read my comments and take them seriously? 
The facilitators gradually introduced participants to the literature on student developmental theory, and, in so doing, helped them conceive of their students developmentally. Rather than see their students in a monolithic fashion, participants were freed to think of behaviors as representative of developmental positions or stages. In tandem with the chapter from Brookfield (1995) on seeking to see oneself as a teacher from a student's perspective, the facilitators asked the members to use at least one classroom assessment technique in their classes and to bring results back to the group. As the new faculty collected data, they gained new insights into their own assumptions and into students' behaviors and perspectives; they became empowered and consequently began to shift from a teacher-centered to a student-centered perspective. There were positive discussions of ways to improve learning. The group was back on track. They were ready to look at Brookfield-and at themselves in relationship to the students-through a new lens. The author's ideas, while deemed controversial by some, prompted important talk and a few "a-ha" experiences. One of the new faculty members posted the following in March:

- "For me, a big breakthrough moment came when Brookfield pushed us to consider the assumptions on which we teach (e.g., discussion circles are democratic, pop media can clarify difficult concepts, etc.). Naming and identifying these assumptions ... has helped me to develop more goal-centered teaching strategies and to make these strategies more 'transparent' to myself and to my students."

\section{Spring Term: Impact}

Using assessment to shape instruction proved to be a crucial practice for all of the members. Across the year, members experimented with assessment techniques in their classes and debriefed during meetings. Formative assessment was helping participants gain an understanding of and appreciation for their students. By getting to know their students, participants were getting to know themselves better at the same time. At different points, each of the four recognized that they needed to be more explicit about the "whys" as well as the "how-to's" that shaped their class activities, assignments, and grading policies. A participant posted the following comment on the discussion board in April:

- “Although I've always strived to help my students become reflective learners, I've realized that I was not being reflective about my own teaching. Over the past year, I've devoted a greater percentage of my prep time to process. Why am I presenting the material in this fashion? What do I hope students take away from the lesson? Am I modeling good problem 
solving? How does this fit into the big picture? What I struggle with still is making my teaching transparent-sharing my process with students."

Participants recognized that there had been growth both individually and collectively. For one, the PLC provided a forum to learn sound teaching techniques. "Teaching is not taught in graduate school, yet somehow we all have to start out our careers being able to teach effectively." The faculty member in her second year not only felt better able to address the needs of freshmen with limited backgrounds in her discipline, but also more "connected to the larger campus community." Her colleagues in the learning community had encouraged her to venture out into campus committee involvement, something she had been uncertain about before. A third noted that the group had moved from serving primarily an affective function for its members to providing all of them with "pedagogical insights.... There is this wonderful sense of shared wisdom, this great exchange of ideas that has made me a more confident, reflective teacher." A fourth, while still "fuzzy" on institutional expectations and a bit confused by student responses, concluded that participation in the PLC had energized her and helped her to recognize that teaching was valued across the campus. She regretted that the group would be disbanding; by spring term, individuals really trusted one another and were able to "discuss things in greater depth."

\section{Projects: Reflection-in-Action}

Each participant in the learning community was required to undertake a project related to teaching: either a course mini-portfolio documenting the instructor's approach to a key course component or a small action research project. Two faculty members elected to create course mini-portfolios. One chose to revise assessments and connect them to course objectives. Her focus emerged from student feedback: students had found her expectations unclear during fall and winter terms. She intended to pilot her revisions during the summer quarter. Her central question was: How can I provide direction without compromising my goal of encouraging creativity and originality? The second member had struggled during fall and winter terms with the diverse academic backgrounds of students in her survey courses. She wanted to explore various innovations in assignments and then determine their effectiveness across the term using classroom assessment techniques and student evaluations. Her central question was: How can 1 meet the radically different needs of majors and nonmajors in the same section of a survey course? 
The other two junior faculty members opted to do action research projects. One project involved students' necessary but weak algebra competencies in a college trigonometry course. By integrating regular opportunities for practice and review throughout the course rather than providing an isolated algebra review at the beginning and by giving mastery quizzes on Blackboard over key algebra topics across the term, the instructor saw significant growth on a basic skills posttest. The second action research project was designed to assess the impact of a service-learning component on student attitudes in a freshman-level English course. The English instructor collected field reports and summative self-assessments in addition to classroom assessment techniques throughout the term in order to address the following questions: What do students gain from service-learning assignments tied to course content? Do education majors find the course more relevant than they have in the past because of the field-based assignments?

\section{Conclusions}

Was the pilot New Faculty Professional Learning Community a success? Information collected for the external evaluation of the grant-funded project in the form of anonymous surveys and focus group interviews left no doubt as to participants' satisfaction with their experiences as learning community members in their first or second year at the college. In response to the survey question "Would you recommend participation in a learning community to a new faculty colleague and why or why not?" participants replied enthusiastically in the affirmative. PLC members felt that they had avoided a sense of isolation, so common and potentially devastating to newcomers. They were able to gain a better understanding of the institutional culture and its expectations-learning about the "intangible aspects of the college," in one participant's terms; they became more aware of resources available to them than they could in a one-day orientation session. They valued a sense of being part of a "faculty" - rather than simply part of a department-because of the close collegial relationships, and even friendships, they had developed in this multidisciplinary group.

Not only did a sense of community and collegiality flourish, but within the context of the group, participants were able to help each other get off to a "quick start." The fall term initiated members into possibilities for the learning community as well as into literature on teaching and learning. While it seemed during the winter quarter-the second phase of the community's development - that what PLC members wanted most were ways to tailor 
their habitual practices and prior convictions about teaching and learning to the Otterbein context, they were able, through supportive and challenging dialogue, use of formative classroom assessments, and construction of an inquiry project, to move beyond a teacher-centered perspective toward a more firmly grounded learning-centered perspective. By the end of the spring quarter, collegial relationships were cemented, and participants had emerged as thoughtful and reflective practitioners. They were at home in a new context, savvy about institutional culture, and willing and able to consider their long-term place within it.

\section{Note}

A generous three-year grant from the McGregor Fund has supported a learning community initiative at Otterbein College, with emphases on new faculty, the scholarship of teaching and learning, diversity, and undergraduate research to date. The case study described in this chapter is part of ongoing assessment underwritten by grant funds.

\section{References}

Angelo, T. A. (1993). A "tcacher's dozen": Fourteen general, research-based principles for improving higher learning in our classrooms. AAHE Bulletin, 45(8), 3-13.

Angelo, T. A., \& Cross, K. P. (1993). Classroom assessment techniques: $A$ handbook for college teachers (2nd ed.). San Francisco, CA: Jossey-Bass.

Baldwin, R. G. (1990). Faculty career stages and implications for professional development. In J. H. Schuster \& D. W. Wheeler (Eds.), Enhancing faculty careers: Strategies for development and renewal (pp. 20-40). San Francisco, CA: JosseyBass.

Boice, R. (1991). Quick starters: New faculty who succeed. In M. Theall \& J. Franklin (Eds.), New directions for teaching and learning: No. 48. Effective practices for improving teaching (pp. 111-121). San Francisco, CA: Jossey-Bass.

Boice, R. (1992). The new faculty member: Supporting and fostering professional development. San Francisco, CA: Jossey-Bass.

Boice, R. (2000). Advice to new faculty members. Needham Heights, MA: Allyn \& Bacon. 
Bransford, J. D., Brown, A. L., \& Cocking, R. R. (Eds.). (2000). How people learn: Brain, mind, experience, and school (Expanded ed.). Washington, DC: National Academies Press.

Brookfield, S. D. (1995). Becoming a critically reflective teacher. San Francisco, CA: Jossey-Bass.

Cox, M. D. (1995). The development of new and junior faculty. In W. A. Wright \& Associates (Ed.), Teaching improvement practices: Successful strategies for higher education (pp. 283-305). Bolton, MA: Anker.

Cox, M. D. (1997). Long-term patterns in a mentor program for junior faculty: Recommendations for practice. In D. Dezure \& M. Kaplan (Eds.), To improve the academy: Vol. 16. Resources for faculty, instructional, and organizational development (pp. 225-268). Stillwater, OK: New Forums Press.

Davis, B. G. (1993). Tools for teaching. San Francisco, CA: Jossey-Bass.

Frederick, P. J. (1989). Involving students more actively in the classroom. In A. F. Lucas (Ed.), New directions for teaching and learning: Vol. 37. The department chairperson's role in enhancing college teaching (pp. 31-40). San Francisco, CA: Jossey-Bass.

Harper, V. (1996). Establishing a community of conversation: Creating a context for self-reflection among teacher scholars. In L. Richlin \& D. DeZure (Eds.), To improve the academy: Vol. 15. Resources for faculty, instructional, and organizational development (pp. 251-266). Stillwater, OK: New Forums Press.

Lewis, K. G. (1994). Using on-going student feedback to increase teaching effectiveness and student learning. Retrieved May 22, 2005, from the University of Texas at Austin, Division of Instructional Innovation and Assessment web site: http://www.utexas.edu/academic/diia/gsi/assessment/ongoing.php

Lucas, C. J., \& Murry, J. W., Jr. (2002). New faculty: A practical guide for academic beginners. New York, NY: Palgrave.

McMillin, L. A., \& Berberet, W. G. (2002). A new academic compact: Revisioning the relationship between faculty and their institutions. Bolton, MA: Anker.

Menges, R. J. (1996). Experiences of newly hired faculty. In L. Richlin \& D. DeZure (Eds.), To improve the academy: Vol. 15. Resources for faculty, instructional, and organizational development (pp. 169-182). Stillwater, OK: New Forums Press.

Meyer, T. (2000). Finding a voice and place in a normative profession. Paper presented at the 80th annual meeting of the American Educational Research Association, New Orleans, LA. (ERIC Document Reproduction Service No. ED 440970) 
Nelson, C. (1997). Tools for tampering with teaching's taboos. In W. E. Campbell \& K. A. Smith (Eds.), New paradigms for college teaching (pp. 51-77). Edina, MN: Interaction Book Company.

New South Wales, Department of Education and Training. (2002). Educational leadership and practice: $A$ review of the literature and an exploration of mentoring practices. Retrieved May 25, 2005, from the New South Wales, Department of Education and Training web site: http://www.schools.nsw.edu.au/edu_leader ship/prof_read/mentoring/intro.php

Rice, R. E., Sorcinelli, M. D., \& Austin, A. E. (2000). Heeding new voices: Academic careers for a new generation (New Pathways Working Paper Series No. 7). Washington, DC: American Association for Higher Education.

Robertson, D. L. (1999). Professor's perspectives on their teaching: A new construct and developmental model. Innovative Higher Education, 23(4), 271-294.

Rosch, T. A., \& Reich, J. N. (1996). The enculturation of new faculty in higher education: A comparative investigation of three academic departments. Research in Higher Education, 37(1), 115-131.

Schön, D. A. (1987). Educating the reflective practitioner: Toward a new design for teaching and learning in the professions. San Francisco, CA: Jossey-Bass.

Sorcinelli, M. D. (1988). Satisfactions and concerns of new university teachers. In J. Kurfiss, L. Hilsen, S. Kahn, M. D. Sorcinelli, \& R. G. Tiberius (Eds.), To improve the academy: Vol. 7. Resources for faculty, instructional, and organizational development (pp. 121-134). Stillwater, OK: New Forums Press. 